\title{
Establishment of Full-fledged Virtual Banking in Bangladesh: Measures to Overcome Obstacles
}

\author{
Md. Omar Faruque ${ }^{1}$, Md. Nurul Kabir Biplob \\ ${ }^{1}$ Department of Finance, Jagannath University, Dhaka, Bangladesh \\ ${ }^{2}$ Department of Finance \& Banking, Begum Rokeya University, Rangpur, Bangladeh \\ Email address: \\ omar1212faruque@gmail.com (Md. O. Faruque), bip06651384@gmail.com (Md. N. K. Biplob)
}

To cite this article:

Md. Omar Faruque, Md. Nurul Kabir Biplob. Establishment of Full-fledged Virtual Banking in Bangladesh: Measures to Overcome Obstacles. International Journal of Economics, Finance and Management Sciences. Vol. 4, No. 1, 2016, pp. 26-30.

doi: 10.11648/j.ijefm.20160401.14

\begin{abstract}
Virtual banking, though a newer concept in Bangladesh, is not new for the world. Since inception full-fledged virtual banking provided some benefits and suffered from some drawbacks. Some countries find this type of banking beneficial while some countries find this as not appropriate based on the countries' macro environmental factors. Some countries prefer remaining within 'brick and click' approach of providing banking services. Later or sooner Bangladesh, one day, will enter into the world of full-fledged virtual banking. This exploratory nature of study aims to find out possible obstacles that Bangladesh may face prior to starting and after starting full-fledged virtual banking operation. These obstacles should be overcome to let full-fledged virtual banking take into operation. The study also suggests that it is the best time to decide whether to remain in 'the brick and click' approach or 'full-fledged virtual banking' approach. This requires analysis of country specific risk and factors and macro environmental factors. Further research is also necessary to prove the validity of the obstacles or challenges stated in the study and take correct policy decision.
\end{abstract}

Keywords: Brick and Mortar, Brick and Click, Virtual Bank

\section{Introduction}

The Bangladesh banking sector relative to the size of its economy is comparatively larger than many economies of similar level of development and per capita income (Sayeed, Bari, Rahman, Azad, Moniruzzaman, \& Shilpi, 2002). It indicates that banking sector has grown very rapidly in the last decade in Bangladesh. Banks are being driven by customer's need, availability of technology, competition to adopt a new information technology and subsequently apply it to service provision (Okunoye, Abiodun, \& Mark, 2007). So it has been the urgency of time to accept newer technologies and inventions in the sector to serve the customers better. Those who are not able to keep pace with the changes are destined to lose the race (Hasan, 2009).

Modern internet banking was introduced in the 1980s due to the availability of the electronic media for the first time. The emergence of internet as a distribution medium of revolutionary potential in the mid 1990s was greeted by the majority of banks with reservation and caution (Singer, Ross, \& Avery). This helps banking businesses transform their existence from physical one to virtual one. The first fully fledged virtual bank in the USA is 'Security First Network Bank (Gandy, 1995). But Manulife Bank of Canada is the first virtual bank in the world. Some says that virtual bank has started with Automated Teller Machine (ATM) (Kass, 1994). Again some says telephone banking and home banking is other forms of virtual bank (e.g. Talmor, 1995; Mahoney, 1994; Sraeel, 1995). A virtual bank can also be defined as a "non-branch bank", while the virtual banking is the provision of banking services through electronic media such as ATM, telephone, personal computers and/or internet (Liao, Shao, Wang, \& Chen, 1999).

Where the banks of the developed countries have taken initiatives to transform their "Brick and click" approach of banking into fully fledged "virtual banking", the banks of Bangladesh are lagging behind even in transforming their "Brick and Mortar" approach of banking into "Brick and click" one let alone virtual banking. Though fully fledged virtual banks exist in the developed countries, the banks face different types of problems in providing services to the customers. It points out that Bangladeshi banks will face more problems in providing services to the customers. But 
problems also exist in establishing fully fledged virtual banks or transforming existing banks into virtual banks in Bangladesh. Here, the expansion of e-banking is beset with several infrastructural, institutional, and regulatory constraints such as inadequate availability of reliable and secure telecommunication infrastructure, absence of a backbone network connecting the whole country, poor ICT penetration in the banking sector, lack of skilled manpower and training facilities, absence of supportive policies, guidelines, rules and regulations relating to e-transactions and the like (Ahmed, Rayhan, Islam, \& Mahjabin, 2011). This study tries to explore the obstacles that may arise in establishing full-fledged virtual bank in Bangladesh.

\section{Literature Review}

Hasan (2009) states that e-banking provides a lot of benefits to the customers as it reduce costs. He also points out that e-banking is going to play a very crucial role in the development of national economy. But the implementation of e-banking requires proper software, infrastructure, skilled manpower, etc. In his study he concludes that e-banking is not at the satisfactory level in case of virtual banking, call center and SMS banking. He emphasized much on security concern.

Ahmed, Rayhan, Islam, \& Mahjabin (2011) try to find out the major problems and prospects of mobile banking in Bangladesh. The study concludes that mobile banking can help expanding virtual bank accounts to the individuals currently do not have bank accounts because of falling costs of mobile phones including airtime. The study states that mobile banking can help save both time and money for the customers and increase the number of clients for the banks. The study argues that in Bangladesh about 95\% area is under the coverage of cellular phone network and it should be utilized as a mean of banking.

Al-Amin \& Rahman (2010)study the application of electronic banking in Bangladesh. The study reveals that ebanking mostly depend on IT. The study recommends that a cmprehensive e-banking will be possible when IT infrastructure, internal network, and country domain will be improved. A high speed fibre optic link and political stability is also required.

Nasri (2011) examines that in Tunisia, demographics factor specifically occupation and instruction significantly impact internet banking behavior. The study concludes that perceived convenience, perceived risk, perceived security and prior internet knowledge have significant impact on behavioral intention to use online banking.

Ali (2010) observed that through successful utilization of e-business Bangladesh can be benefitted. Alam, Magboul, \& Raman (2010) states that lack of efficient infrastructure, lack of training of the employee, investment on information technology are major challenges faced by Sudanese banks in implementing online banking. Biswas, Taleb, \& Shinwary (2011) state that appropriate software, technology, infrastructure, skilled manpower and cyber law are crucial for e-banking implementation in Bangladesh.

Yaghoub \& bahmani (2010) studies the factors affecting adoption of online banking in Isfahan province of Iran. They developed a theoretical model by integrating Technology Acceptance Model (TAM) and Theory of Planned Behavior. The study indicates that the intention to use online banking is positively affected by perceived behavioral control and perceived usefulness. The study showed that Perceived behavioral control, perceived ease of use, perceived ease of usefulness, subjective norm and attitude have positive impact in the adoption of online banking.

\section{Objectives of the Study}

- To identify the major obstacles need to overcome to establish full fledged virtual bank in Bangladesh.

- To analyze the status of full-fledged virtual banking all over the world.

- To analyze the status of full-fledged virtual banking in Bangladesh

\section{Methodology of the Study}

It is basically an exploratory type of research. In the study qualitative research methodology and secondary sources of data have been used. Secondary data mainly involves different articles and website information. Secondary sources of data have been used to:

i. analyze present status of virtual bank around the world;

ii. analyze present status of virtual banking in Bangladesh;

iii. analyze problems of virtual banking in Bangladesh;

\section{Limitations of the Study}

The main limitation of the study is the unavailability of relevant information. The problem is acute because fully fledged virtual bank did not get universal acceptance by the banks all over the world. In Bangladesh getting the relevant information about the topic 'fully fledged virtual bank' is impossible due to the non-existence of this type of bank. There are also insufficiencies of previous works regarding the topic. For this reason an exploratory research has been made to explore the knowledge and further study is required to achieve better conclusion.

\section{Status of Virtual Bank}

\subsection{Status of Virtual Bank Around the World}

There is controversy regarding the first virtual bank. Some believe that 'Security First Network Bank' of USA is the first virtual bank (Liao, Shao, Wang, \& Chen, 1999) but it is not true. 'Manulife Bank' of Canada is the first virtual bank. 'Security First Network Bank' is the first virtual bank in USA and was established in October 1995. 'Manulife Bank' of Canada was established on January 1, 1993. Manulife financial merged Cabot Trust Company, Huronia Trust 
Company and the Regional Trust Company to establish the bank. Later it sold its branch network to another bank and became the first fully fledged virtual bank in Canada.

World's 10 top ranked virtual banks 2015 are:

a) Ally bank

b) Bank5 Connect

c) Discover Bank

d) GE Capital Bank

e) Synchrony Bank

f) CIT Bank

g) Sallie Mae Bank

h) TIAA Direct

i) First Internet Bank

j) Barclays Bank

In U.S the spread of automated teller machines (ATM), the rise of online and mobile banking and the formation of nonbank sources of credit and transaction services have reduced customer's day to day dependence on physical offices. Nevertheless, as of June 2014, some 6,669 banks and thrifts continued to operate 94,725 brick-and-mortar offices, providing testament to the enduring value of physical access to banking services in an increasingly virtual banking world (FDIC_Federal Deposit Insurance Corporatin, 2015).

In North America, a study reveals that bank customers prefer channels other than branch when the transaction is simple (Ericsson, Farah, Vermeiren, \& Buckalew, 2012). One interesting thing that reveals in North America is that respondents are most interested in specialty branch banking concept (Ericsson, Farah, Vermeiren, \& Buckalew, 2012). In North America the adoption of virtual banking increases and branch visit declines but respondents also like physical branch format with advice and personal attention (Ericsson, Farah, Vermeiren, \& Buckalew, 2012). The key perceived advantages of virtual banking demonstrated by the respondents of North America are: time saving, greater flexibility in banking hour of operation, and access to specialist unavailable at the local branch (Ericsson, Farah, Vermeiren, \& Buckalew, 2012). The drawbacks are: concern about security of information transmitted online, the lack of personal touch, and potential difficulties using the format (Ericsson, Farah, Vermeiren, \& Buckalew, 2012).

In Europe, the evidence of economies of scope of information and communication technologies is little. With an internet the performance of banking group is poor. Because the initial investment in technology has proved higher than any cost saving. Internet banks seem to fail creating synergies with other banking activities (Arnaboldi \& Claeys, Innovation and performance of European banks adopting Internet).

So, it is evident that there is a mix effect regarding the adoption of fully fledged virtual banking even in the developed countries. Sometimes it is better to operate with fully fledged virtual banking and sometimes it is better to operate with brick and click facilities. Some country specific and macroeconomic considerations should also be considered.

\subsection{Status of Virtual Banking in Bangladesh}

There are two extreme points of providing banking services. One is using physical branches and the other is without branches. In between them a hybrid approach exist which is called 'brick and click' approach. Bangladesh is in the process of transforming into 'brick and click' approach of providing banking services. So it is very clear that it will take a lot of time to enter into the full fledged virtual world of providing banking services for Bangladeshi banks.

Entrance into the new era begins when Bangladesh Bank introduces online payment system. As a result, one can transfer funds, pay utility bills on the net and use local currency credit cards for online transactions within the country. It is being considered the first step of toward fullfledged online banking (Hamidur, 2009).

In Bangladesh, Dutch Bangla Bank is the pioneer of establishing online banking system. It is the first and country's only local bank to have an automated banking system. It has completed its automation process in 2003. It has the country's highest number of ATM booths. It is the first bank of Bangladesh to offer SMS banking.

Among the other banks, Premier Bank has set up Wide Area Network using Radio, Fibre-Optics \& other communication systems to provide branch banking to its customers (Premier Bank Annual Report, 2009). The bank has been giving SMS banking services since 2006. Using SMS banking, customers can get real time account information 24 hours a day and 7 days a week (Biswas, Taleb, \& Shinwary, 2011).

The customers of Prime Bank can verify account balances, transfer funds and pay loans. They also can monitor account activity, transfer funds at convenience, and get real time account balance. With the help of Prime bank's bill payer program, customers can pay their bills (Biswas, Taleb, \& Shinwary, 2011).

Islami Bank Bangladesh Ltd. (IBBL) has introduced ATM, SMS banking and internet banking. The internet based banking of IBBL is termed as I Banking which has been introduced since 2009. For both local and international use IFIC Bank issues VISA Credit Cards. Local cards can be used at ATM displaying VISA logo within Bangladesh and international cards can be used in any ATM for withdrawal of cash. Both local and international cards can be used to purchase goods and services at any POS displaying VISA logo. The bank also provides its customers the opportunity of SMS banking and Card service (Biswas, Taleb, \& Shinwary, 2011).

These are some examples of the present status of internet banking provided by Bangladeshi banks. It is very clear from the above examples that the e-banking services provided by the banks in Bangladesh could be divided in three groups: ATM Services, Internet Banking (i-Banking), and SMS Banking (Biswas, Taleb, \& Shinwary, 2011).

But these are not the actual flavor of virtual banking. Fullfledged virtual banking means much more. These can be regarded as primary signs of the transformation process. But 
the question is how long it will take to transform, what are the challenges the banks facing or may face, is it feasible for all banks to transform into virtual one, does macro environmental factors of Bangladesh support fully fledged virtual banking. It is evident that each country has its own country specific features. As a result in some countries virtual banking is more successful and in some other countries 'Brick and Click' banking is more successful. In this respect we can say that country specific features appear to be more important in explaining differences across banks (Arnaboldi \& Claeys, 2008).

\section{Obstacles to Overcome}

Obstacles or challenges of virtual banking can be divided into two categories. First category includes the obstacles that may come prior to starting full-fledged virtual banking operation. Second category includes the obstacles that may come after the inception of full-fledged virtual banking operation.

\subsection{First Category}

The obstacles falls under the category are:

a) Lack of infrastructure: Infrastructure includes communication channel, availability of technological and technical support. Having enough communication channels is necessary but it is also necessary that the communication channels must be efficient, competitive, competent, cost effective and supportive to the services (Biswas, Taleb, \& Shinwary, 2011).

b) Lack of proper education: Though the passing rate of Bangladesh is increasing, but the students all over the Bangladesh have little knowledge regarding computer and computer based technology. It is important to take necessary steps right at the moment to make future clients of virtual banking accustomed to different types of computer based technology. Computer and related devices that may be used as a tool of doing banking should be made available all over the Bangladesh.

c) Internet Access: The internet access rate has increased in recent years. But it is still very low in consideration of the total population. Bangladesh has entered into the $3 \mathrm{G}$ world which is a very good sign. The cost of internet access is another challenge. One positive sign is that among the internet users the large proportion is held by the young generation who are the future users of full-fledged virtual banking.

d) Risk Factors: Risk factors such as acceptance by the users, competitive cost, value and quality of service, account information hacking can play an important role in this aspect. How to deal with these risk factors can be a major concern.

e) Qualified human resource: Lack of knowledge of top management and insufficiency of qualified human resources may be proved to be a major obstacle. It is the high time we should start upgrading the existing software and make the human resources ready for the future.

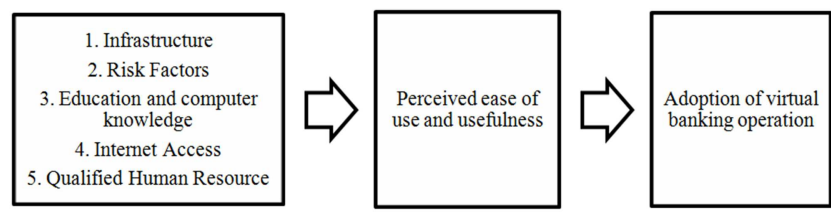

Figure 1. Adoption of virtual banking.

These obstacles directly or indirectly influence perceived ease of use and usefulness that will lead to the adoption of virtual banking operation in Bangladesh. Hence this model requires further verification.

\subsection{Second Category}

a) No physical Branch to accept deposit: There are any physical branches to accept deposit meaning that customers should use direct deposit or mail deposit. After the inauguration of full-fledged virtual banking this may be proved as a great drawback.

b) Customers miss personal service: In virtual banking customers miss personal service of physical branch. So improvement or creation of service that will perfectly substitute the missing service may be a major concern for future virtual banks of Bangladesh.

c) Spyware and viruses: The banks of developed countries are facing challenges regarding attack by spyware, viruses and hackers. In future, the programmers will develop more dangerous viruses that will be a great concern for future Bangladeshi full-fledged virtual banks.

d) Valuation Problem: There are no specific guidelines of valuing ICT based firms in Bangladesh. So, when fullfledged virtual bank will start operation in Bangladesh, valuing those banks can be very difficult.

\section{Conclusion}

Virtual banking has added a new dimension in the field of banking. It possesses a lot of advantages as it lowers overhead cost, bank a/c fees, ensures higher interest income for both customers and banks, increases customers switching cost, etc. Despite the advantages, full-fledged virtual banking has not globally accepted all over the world. Some countries prefer a hybrid approach i.e. 'Brick and Click' banking. Some prefer special branch banking. It is because of the drawbacks that full-fledged virtual banking holds. It is the best time for Bangladesh to analyze the challenges that hinder the adoption of full-fledged virtual banking and the challenges that will face by the Bangladeshi banks after starting full-fledged virtual banking operation. It is also important to analyze the country specific factors and macro environmental factors to understand whether they allow full-fledged virtual banking in Bangladesh. This will establish firm confidence regarding whether to remain in the 'Brick and Click' 
approach or to go forward.

\section{References}

[1] Ahmed, S. S., Rayhan, S. J., Islam, M. A., \& Mahjabin, S. (2011, June). Problems and prospects of mobile banking in Bangladesh. Journal of Information Engineering and Applications, pp. 16-35.

[2] Alam, N., Magboul, I. H., \& Raman, M. (2010). Challenges Faced by Sudanese Banks in Implementing Online. Journal of Internet Banking and Commerce, 1-9.

[3] Al-Amin, S., \& Rahman, S. S. (2010). Application of electronic banking in Bangladesh: An Overview. Bangladesh Research Publications Journal, 172-184.

[4] Ali, M. M. (2010, June). E-Business and on line banking in Bangladesh:. AIUB Bus Econ Working Paper Series/ Office of Research Publication.

[5] Arnaboldi, F., \& Claeys, P. (n. d.). Innovation and performance of European banks adopting Internet.

[6] Arnaboldi, F., \& Claeys, P. (2008, 11). Internet Banking in Europe: a comparative analysis. Research Institute of Applied Economics.

[7] Biswas, D. S., Taleb, A., \& Shinwary, S. S. (2011). Electronic Banking in Bangladesh: Security. Canadian Journal on Scientific and Industrial Research, 181-194.

[8] Ericsson, J., Farah, P., Vermeiren, A., \& Buckalew, L. (2012). Winning Strategies for Omnichannel Banking.

[9] Gilani, N. (n. d.). Retrieved 2013, from eHow Web site: $\mathrm{http} / / /$ www.ehow.com/about_6717015_electronic-bankingdefinition.html.
[10] Hamidur. (2009). Online Banking begins in Bangladesh.

[11] Hasan, K. (2009). E-Banking in Bangladesh: The Future of Banking. 1-19.

[12] Liao, S., Shao, Y. P., Wang, H., \& Chen, A. (1999). The adoption of virtual banking: an empirical study. International Journal of Information Management, 63-74.

[13] Nasri, W. (2011). Factors Influencing the Adoption of Internet Banking in Tunisia. International Journal of Business and Management, 143-160.

[14] Okunoye, A., Abiodun, O. B., \& Mark, F. (2007). IT Innovations and E-service Delivery: An Exploratory Study. 9th International Conference on Social Implications of Computers in Developing Countries. Sao Paolo.

[15] Rahman, D. M., Uddin, D. M., \& Siddiqui, S. A. (2012). Problems and Prospects of E-Banking in Bangladesh. International Journal of Scientific and Research Publications, $1-6$.

[16] Sayeed, Y., Bari, M., Rahman, M. M., Azad, W. A., Moniruzzaman, M., \& Shilpi, L. M. (2002). Swinging Bangladesh: Not very promising.

[17] Shamsuddoha, M. (n. d.). Electronic Banking in Bangladesh. Retrieved 2012, from http://ssrn.com/abstract $=1418288$.

[18] Singer, D., Ross, D., \& Avery, A. (n. d.). The Evolution of Online Banking.

[19] Yaghoub, N.-M. i., \& bahmani, E. (2010, September 9). Factors Affecting the Adoption of Online Banking: An Integration of Technology Acceptance Model and Theory of. International Journal of Business and Management, pp. 159165.

[20] FDIC, Quarterly (2015). Volume 9, No.1, pp 37-51. 